\title{
Jérôme-Pierre Gilland, Les Conteurs ouvriers
}

\section{Claire Le Guillou}

\section{(2) OpenEdition \\ Journals}

\section{Édition électronique}

URL : http://journals.openedition.org/studifrancesi/5350

DOI : 10.4000/studifrancesi.5350

ISSN : 2427-5856

\section{Éditeur}

Rosenberg \& Sellier

\section{Édition imprimée}

Date de publication : 1 décembre 2016

Pagination : 533

ISSN : 0039-2944

\section{Référence électronique}

Claire Le Guillou, « Jérôme-Pierre Gilland, Les Conteurs ouvriers », Studi Francesi [En ligne], 180 (LX | III) | 2016, mis en ligne le 01 janvier 2017, consulté le 18 septembre 2020. URL : http://

journals.openedition.org/studifrancesi/5350 ; DOI : https://doi.org/10.4000/studifrancesi.5350

Ce document a été généré automatiquement le 18 septembre 2020.

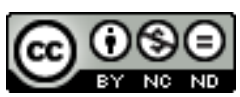

Studi Francesi è distribuita con Licenza Creative Commons Attribuzione - Non commerciale - Non opere derivate 4.0 Internazionale. 


\title{
Jérôme-Pierre Gilland, Les Conteurs ouvriers
}

\author{
Claire Le Guillou
}

\section{RÉFÉRENCE}

JÉRÔME-PIERRE GILLAND, Les Conteurs ouvriers, Bassac, Éditions Plein Chant, 2015, «Voix d'en bas», 219 pp.

1 En 1979, Edmond Thomas publiait Voix d'en bas: la poésie ouvrière XIX siècle chez Maspero. D'autres publications depuis ont été consacrées aux poètes-ouvriers. Citons par exemple l'ouvrage collectif La Poésie populaire en France au XIX siècle (Tusson, Du Lérot, 2005). En revanche, aucun éditeur jusqu'à maintenant n'avait souhaité ou eu le courage de faire réentendre l'une de ces «voix d'en bas». Les livres de Marie-Eléonore Magu, Charles Poncy, Savinien Lapointe, Jérôme-Gilland ne sont accessibles que dans des éditions du XIX ${ }^{e}$ siècle. Il serait plus exact désormais d'écrire «n'étaient accessibles», car Edmond Thomas, qui dirige les Éditions Plein Chant, vient de rééditer l'une des œuvres de Jérôme-Pierre Gilland dans une collection nommée justement «Voix d'en bas».

Cette élégante petite collection blanche - petite uniquement par son format - nous offre l'occasion de lire Les Conteurs ouvriers. Cette réédition, qui reprend comme dans l'édition originale publiée en 1849 la préface rédigée par George Sand, est accompagnée d'une étude de Jean Prugnot consacrée à Jérôme-Pierre Gilland, ainsi que d'un compte rendu publié en mai 1849 dans «L'Atelier». L'étude de Jean Prugnot avait été publiée initialement en novembre 1946 dans «Les Cahiers du peuple». Elle méritait assurément d'être republié. Toutefois un texte de présentation de l'œuvre et de l'auteur conçu pour la circonstance aurait été également de bon ton. À cela s'ajoute un «Petit lexique» qui s'avère le bienvenu. Une «Petite bibliographique» aurait éventuellement constitué un heureux pendant à ce «Petit lexique». Outre les deux références bibliographiques signalées en notes (Jean Prugnot, J.-P. Gilland et l'affaire du Vote universel, «Maintenant», 1946, n. 4 et Jacques Marillier, Un serrurier parisien pendant 1848, Jérôme-Pierre Gilland, 
«Maintenant», 1948, n. 9-10, pp. 288-309), auraient pu y figurer l'article de Nathalie Vincent Munnia, Magu, Gilland, Marc Gilland: une famille de poètes ouvriers sur trois générations (in Pères et fils, rapports intergénérationnels dans les dynasties d'écrivains et d'artistes, Clermont-Ferrand, Presses universitaires Blaise Pascal, 2012, pp. 197-211) et l'ouvrage d'Alain Vivien, Jérôme Gilland (Saint-Maur-des-Fossés, Éditions du Parc, 2014).

Il faut signaler par ailleurs que les soixante-cinq pages de poésie figurant dans l'édition originale ont été supprimées. A contrario, les cinq nouvelles ou contes sont donnés dans leur intégralité. Faut-il voir là une volonté de conserver une unité de genre, d'évincer des pièces poétiques jugées de piètre facture, le souhait de proposer un volume de proportion raisonnable ou bien encore de présenter les textes qui permettent de mieux cerner l'itinéraire de Gilland? De fait, ce choix éditorial offre la part belle au conte intitulé Les aventures du petit Guillaume du Mont-Cel. Gilland, comme l'indique George Sand dans sa préface, lui avait déclaré: «Vous trouverez presque tous les détails de mon premier âge, dans le conte intitulé les Aventures du petit Guillaume; sauf le chapitre de la domesticité chez les Anglais, qui est une fiction, tout le reste est de l'histoire» (p.11). Cette histoire, terme qui figure dans le texte de la romancière en italique faute de majuscule, mérite d'être redécouverte non seulement parce qu'elle permet d'appréhender le destin singulier d'un enfant mais aussi celui de toute la classe laborieuse de son temps. Si cette histoire mérite d'être redécouverte, les Éditions Plein chant ont, quant à elles, le mérite de la faire redécouvrir. 